\title{
Influence of Media Geometry on Wet Grinding of a Planetary Ball Mill
}

\author{
Italo Leite de Camargo ${ }^{a, b} * \mathbb{\complement}$, João Fiore Parreira Lovo ${ }^{a}{ }^{\circledR}$, Rogério Erbereli $^{a}{ }^{\circledR}$, Carlos Alberto Fortulan $^{a} \unrhd$ \\ ${ }^{a}$ Universidade de São Paulo - USP, Escola de Engenharia de São Carlos - EESC, Departamento de \\ Engenharia Mecânica, Laboratório de Tribologia e Compósitos, Trabalhador São Carlense, 400. \\ São Carlos, SP, Brasil. \\ ${ }^{b}$ Instituto Federal de Educação, Ciência e Tecnologia de São Paulo - IFSP, Primeiro de Maio, 500. \\ Itaquaquecetuba, SP, Brasil.
}

Received: July 16, 2019; Revised: October 17, 2019; Accepted: November 18, 2019

\begin{abstract}
Planetary ball mills are able to perform dry and wet grinding. Most experimental analyses and computer simulations in this field are mainly about dry grinding. In order to empirically evaluate the wet grinding process, test grindings benches were manufactured, calcined alumina powder was ground, and the particle distribution analyzed. Effects of the media geometry (size and shape) on particle distribution, morphology, and phase composition of ground alumina were investigated. Smaller media leads to smaller particle size and cylindrical media provides a poor grinding performance but its product has the narrower particle size distribution. Alumina showed no phase change in the grinding tests. The experiments presented in this study can be used as an aid in the proper choice of grinding media or even to validate emerging models capable of predicting breakage in wet grinding.
\end{abstract}

Keywords: Alumina, planetary mill, milling parameters, wet grinding.

\section{Introduction}

Grinding has been an important operation in several fields such as chemical, pharmaceutical, and material industries. Fine grinding has become even more important due to nanotechnology and nanomaterials. Planetary ball mills, in which rotating jars are installed on the revolving disk, generate fine powder through a high-energy process ${ }^{1}$, which are known as the most powerful tools in synthesizing particles ${ }^{2}$. Some non-traditional applications have emerged as encapsulation and stabilization of $\beta$-Carotene ${ }^{3}$, purifying multi-walled carbon nanotubes ${ }^{4}$, and mechanochemical synthesis of calcium phosphates ${ }^{5}$. The last two brings an old discussion: dry or wet grinding, which one is better for the process? There is no single answer and everything depends on several factors of the raw material and the applications of the product.

Some experimental studies relate grinding performance and media shape in different types of mill. In a laboratory mill, cylindrical shaped grinding media produces faster breakage rates than ball charges under the same conditions ${ }^{6}$. According to Ipek et al. ${ }^{7}$, it might be explained due to the contact mechanism and the higher surface area of the cylindrical media. On the other hand, Kelsall et al. ${ }^{8}$ found that cylinder and cubes always produce fewer fines than spheres in a continuous wet ball mill. The authors explain that this difference is due to the change from point contact for spheres to a range of different types of contact for the other shapes. However, all these studies considered powder feed size of hundreds of microns.

The influence of the mean particle size $\left(\mathrm{D}_{50}\right)$ on products properties such as toughness is already well known for decades ${ }^{9}$. Most studies about products obtained by grinding

*e-mail: italo.camargo@ifsp.edu.br in a planetary ball mill just use $\mathrm{D}_{50}$ as a reference of grinding performance. However, there are other parameters of a particle distribution that may have effects on the processed product. For example, bulk densities, shrinkage, and strength increase, while radial density gradient diminishes upon increasing the amount of the finest fraction in the raw material of uniaxially die-pressed alumina refractories ${ }^{10}$. Increasing the relative dispersion of the particle size distribution improves the sintering ability of Silicon Carbide ${ }^{11}$. Particle size has been studied even in environmental issues and found as a key factor to the dustiness of the raw materials (their tendency to generate dust on handling) ${ }^{12}$. Moreover, choosing the suitable particle distribution width is an important aspect in the shaping form processes of ceramics. For instance, a slip casting process requires a wider distribution than dry pressing. Choosing the proper grinding media leads to the appropriate grinding product.

Zhang et al. ${ }^{13}$ experimentally studied the effect of the ball-to-powder ratio, size of milling balls, medium and rotation speed in the wet grinding of a planetary ball mill considering just the mean particle size concerning particle size distribution. In this manuscript, wet grindings on a planetary mill were performed in order to analyze the influence of media geometry (size and shape) on mean particle size, the width of the particle size distribution, morphology, and phase composition.

\section{Materials and Methods}

A planetary mill test bench with revolution radius of 150 $\mathrm{mm}$ has been manufactured. The equipment was designed to provide rotation-to-revolution speed ratio of -2 (where the negative sign indicates opposite directions). Such ratio 
was chosen aiming greater grinding efficiency according to Mio et al. ${ }^{14}$. The bench was based on Brazilian Patent BR2020180676232 ${ }^{15}$, which project was described by Camargo et al. ${ }^{16}$. However, this larger planetary mill should withstand a greater load than the friction wheels would resist, gears were chosen for motion transmission, as shown in Figure 1. The central gear is attached directly to the motor flange and stands still and the rotating parts fixed in the motor shaft.

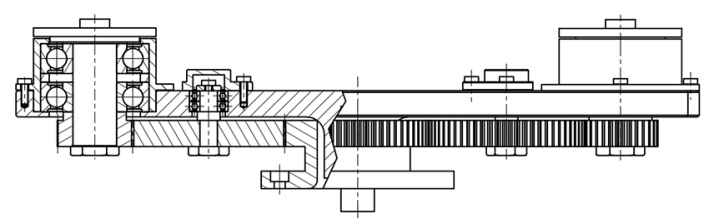

Figure 1. Mechanical Design of the planetary mill.

In order to evaluate the influence media geometry on wet grinding of a planetary mill, calcined alumina powder, considered a universal hard material reference, was ground under different conditions. The material used was a commercially pure $(99.7 \%) \mathrm{Al}_{2} \mathrm{O}_{3}$ powder (APC-G, ALCOA) with a median particle size equal to 4.2 micrometers.

Jars (coated with alumina) with $360 \mathrm{ml}$ (Ø70 mm x h94 $\mathrm{mm}$ ) were used. In all the tests, the jar was filled with $10 \mathrm{vol} \%$ of alumina powder, $23 \mathrm{vol} \%$ of distilled water, $33 \mathrm{vol} \%$ with zirconia media. In addition, Ammonium Polyacrylate was added as a deflocculant ( $1 \mathrm{wt} \%$ of the mass of the powder).

The ball filling ratio around one-third vol\% was chosen according to Rosenkranz et al. ${ }^{17}$ which showed that it would lead to a cascading motion and most effective grinding (assuming that the ball motion is not affected by medium or mill feed). Zirconia was chosen as media due to the fact that it has a larger density $\left(5.68 \mathrm{~g} / \mathrm{cm}^{3}\right)$ and fracture toughness compared to other ceramic materials, such as alumina $\left(3,95 \mathrm{~g} / \mathrm{cm}^{3}\right)$ and Chen et al. ${ }^{18}$ showed that higher media density is beneficial to obtain finer products. Thus, zirconia balls $(\varnothing=3 \mathrm{~mm}, \varnothing=5 \mathrm{~mm}$ and a mixture with half of each) and cylinders $(\varnothing=5 \mathrm{~mm} \times 5 \mathrm{~mm})$ were used as grinding media.

Grinding in a planetary mill is a high-energy process that occurs in jars, which have a high thermal barrier (due to their ceramic coating). According to Takacs et al. ${ }^{19}$, jars of the planetary mill can easily exceed $200{ }^{\circ} \mathrm{C}$. Whereas the fluid used as a solvent was water, with a limited boiling point, the temperature inside the jars has to be controlled. The internal temperature was measured after pre-set grinding times: the jar was immediately opened, a probe of a digital thermometer (MT-525, Minipa) inserted, and it was measured temperatures as high as $75^{\circ} \mathrm{C}$ after 10 minutes, which was the maximum continuous operating time established. For longer grinding, operating cycles followed by pause were used until the temperature dropped close to room temperature, as suggested by Huller et al. ${ }^{20}$. The grinding time in each sample was 30 minutes ( 3 cycles) and the employed revolution was approximately $400 \mathrm{rpm}$.

The particle distributions of the raw material and ground alumina were analyzed by a sedigraph $\AA$ known for using sedimentation and photon absorption to determine particle size. For this procedure, the samples were diluted in distilled water, forming a solution with $40 \%$ solids content and then subjected to ultrasonic dispersion for 5 minutes.

Moreover, the morphology of the grinding samples and the initial powder were analyzed by a scanning electron microscope. Lastly, a possible change in the phase composition was verified by X-ray powder diffraction. For these two analyzes, 5 grams of each sample were dried in the oven at $110^{\circ} \mathrm{C}$ for 12 hours. In order to alleviate the usual agglomeration of the drying process, each sample was subsequently submitted to 5 minutes of manual action in the mortar and pistil.

\section{Results}

Figure 2 shows the media geometry effect on cumulative particle size distribution: smaller media leads to smaller particle size, as seen in dry grinding ${ }^{21}$. Even though smaller balls provide lower impact energy, larger balls cause agglomeration which decreases the particle size reduction ${ }^{13}$. In Figure 3, it can be observed that the only sample with mono-modal curve is the ball with diameter of $3 \mathrm{~mm}$ while larger media provided bi-modal curves.

It is interesting to note that a mixture between balls of $3 \mathrm{~mm}$ and $5 \mathrm{~mm}$ leads to a final product very similar to the one that uses just $5 \mathrm{~mm}$ balls. Another interesting point is that cylinders presented a poor performance in the wet grinding of a planetary mill. On the other hand, considering the width of the particle size distribution $\left(W_{p s d}\right)$, that can be calculated using Equation 1, the cylinders have the narrower particle size distribution. $\mathrm{D}_{10}, \mathrm{D}_{50}, \mathrm{D}_{90}$ and $W_{p s d}$ are summarized in Table 1.

$$
\text { Wpsd }=(\text { D90-D10) } / \text { D50 }
$$

The morphology of the initial powder and grinding samples is shown in Figure 4. Figure 4a shows the raw material. In Figures 4b, 4c, and 4d, corresponding to ground samples with spherical grinding media, the reduction of particle size is observed presenting particles below $0.5 \mu \mathrm{m}$ and the presence of a remaining fraction of larger particles. In contrast, in Figure 4e, which represents cylindrical media, particles as large as the originals were not observed. This can be explained due to non-point contact, i.e. it preferentially breaks the larger particles that are between the contact lines of the elements. In general, agglomeration of the smaller particles is observed in the milling samples, which may have been caused by the drying process, not necessarily representing the condition of the slurry after grinding. 


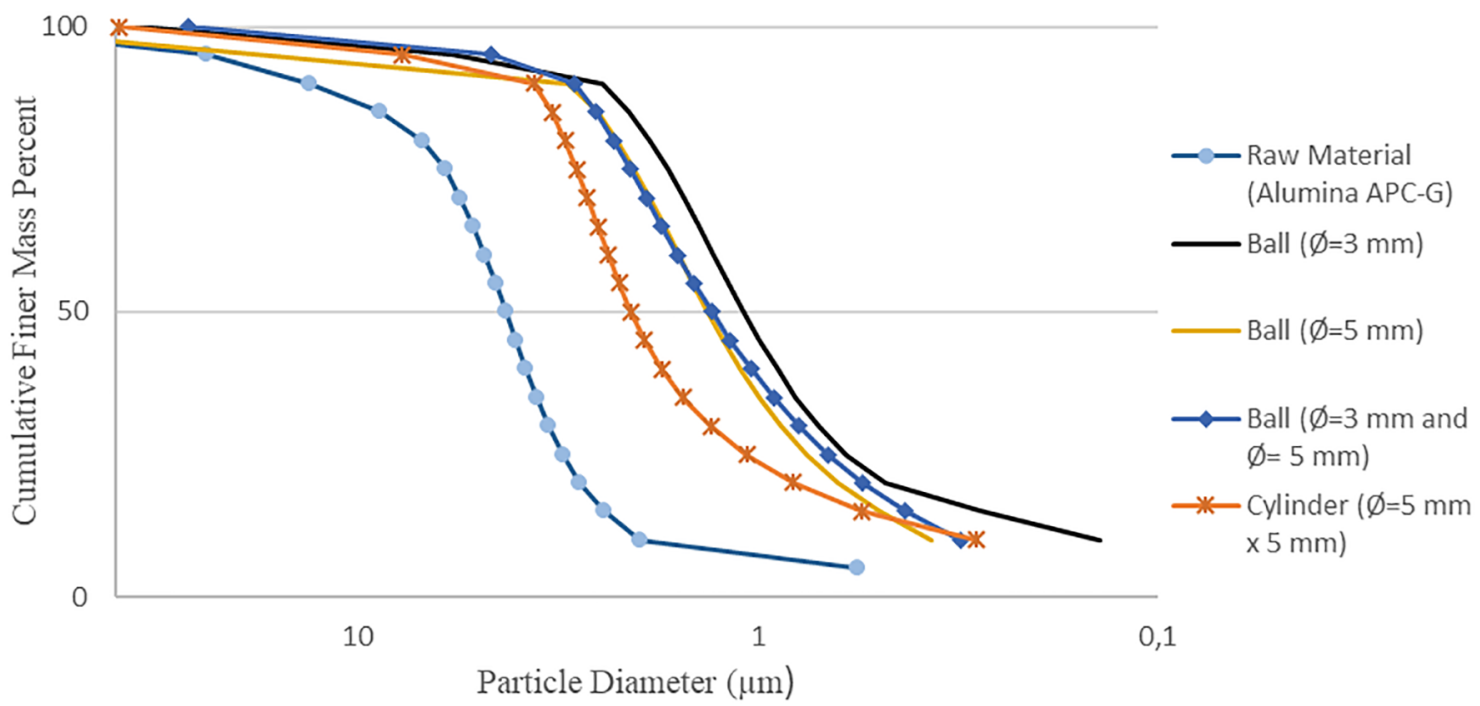

Figure 2. Cumulative particle size distribution: effect of media size and shape.

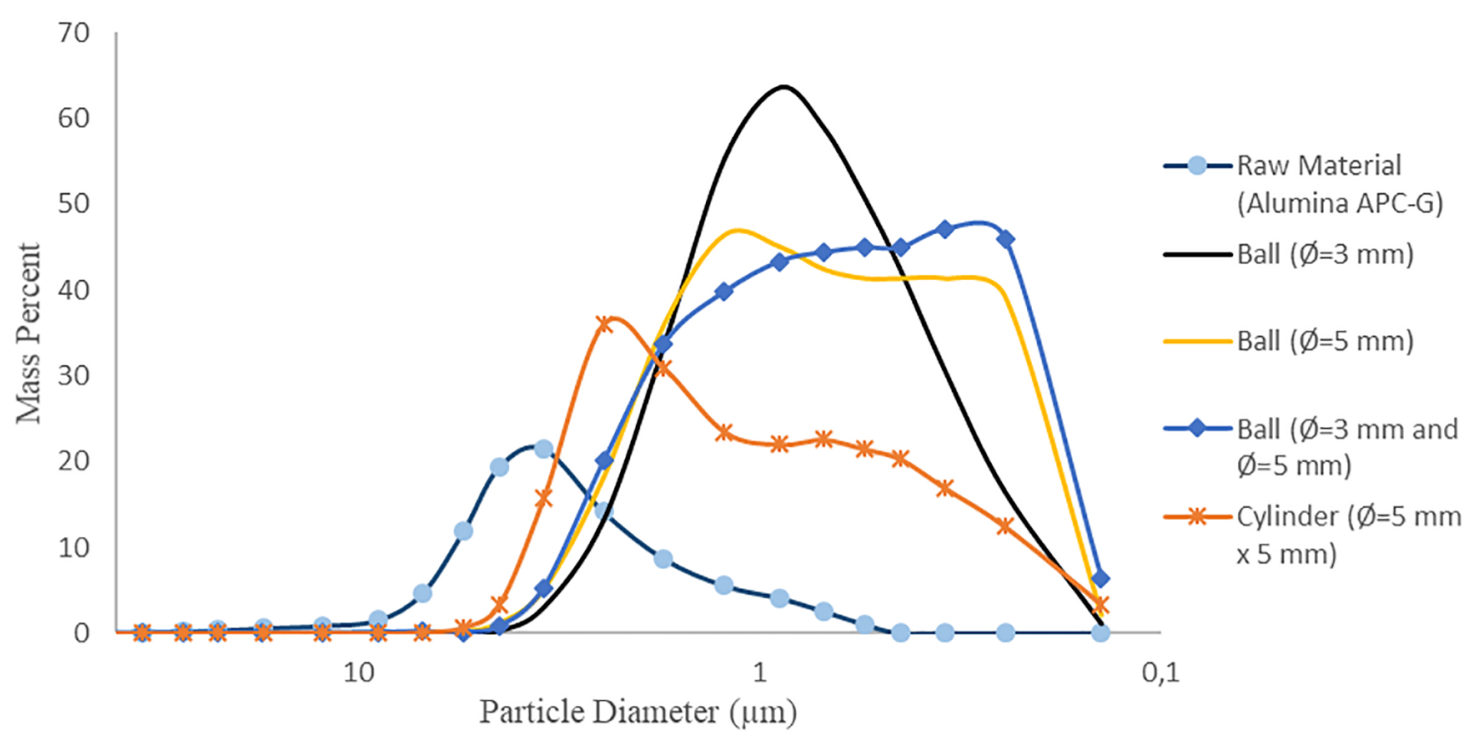

Figure 3. Particle size distribution: effect of media size and shape.

Table 1. Particle size distribution summary

\begin{tabular}{lcccc}
\hline & D10 & D50 & D90 & Wpsd \\
\cline { 2 - 5 } & $(\boldsymbol{\mu m})$ & $(\boldsymbol{\mu m})$ & $(\boldsymbol{\mu m})$ & $(\boldsymbol{\mu m})$ \\
\hline $\begin{array}{l}\text { Raw Material (Alumina } \\
\text { APC-G) }\end{array}$ & 1.96 & 4.26 & 13.09 & 2.61 \\
Ball $(\varnothing=3 \mathrm{~mm})$ & 0.14 & 1.08 & 2.45 & 2.14 \\
Ball $(\varnothing=5 \mathrm{~mm})$ & 0.37 & 1.33 & 2.98 & 1.96 \\
Ball $(\varnothing=3 \mathrm{~mm}$ and $\varnothing=5 \mathrm{~mm})$ & 0.31 & 1.30 & 2.86 & 1.96 \\
Cylinder $(\varnothing=5 \mathrm{~mm} \times 5 \mathrm{~mm})$ & 0.28 & 2.07 & 3.61 & 1.61 \\
\hline
\end{tabular}

Figure 5 shows XRD patterns of raw and ground alumina, indicating that the peaks are maintained after grinding in the planetary mill, thus not having significantly affected the crystalline structure of alumina. There was some reduction in the intensity of diffracting peaks which can be associated with internal strain ${ }^{13}$ and lattice distortion ${ }^{18}$.

\section{Discussion}

When analyzing the data from the milling experiments, it is clear that a product cannot be characterized just by its mean particle size. Although much effort has been made to predict the effect of grinding parameters on the $\mathrm{D}_{50}$ of fabricated powders, associating them with (specific) impact energy and frequency of impacts in dry grinding, this set of experiment showed that a deeper study should be made in wet grinding, looking forward to find the relation between the grinding parameters and the final product features, such as $\mathrm{D}_{10}, \mathrm{D}_{50}, \mathrm{D}_{90}$, distribution span, and morphology. 

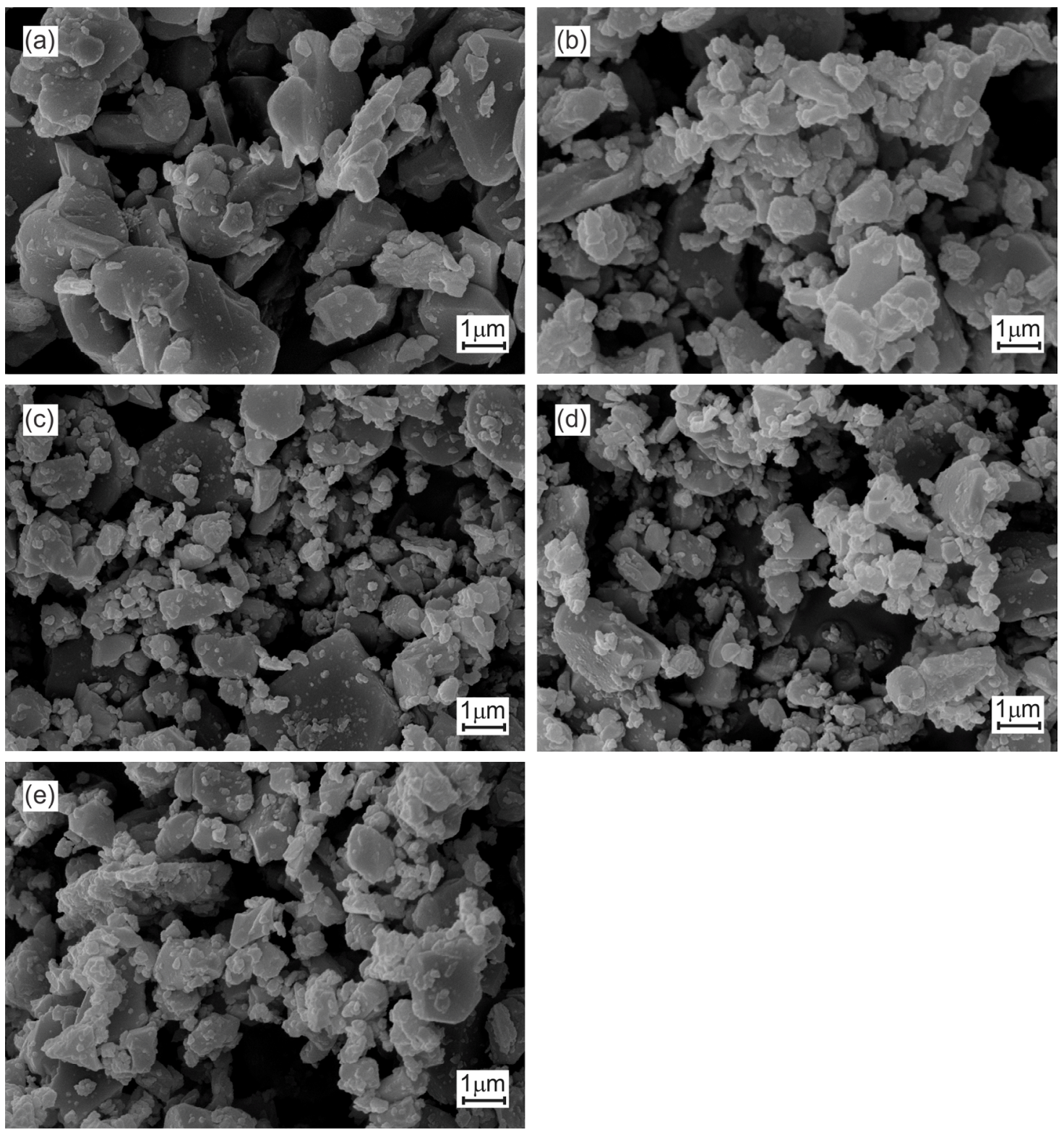

Figure 4. Scanning electron microscope images. (a) Raw material (alumina APC-G). (b) Ball ( $\varnothing=3 \mathrm{~mm})$. (c) Ball (Ø=5 mm). (d) Ball ( $\varnothing=3$ and $5 \mathrm{~mm}$ ). (b) Cylinder ( $\varnothing=5 \mathrm{~mm} \times 5 \mathrm{~mm}$ ).

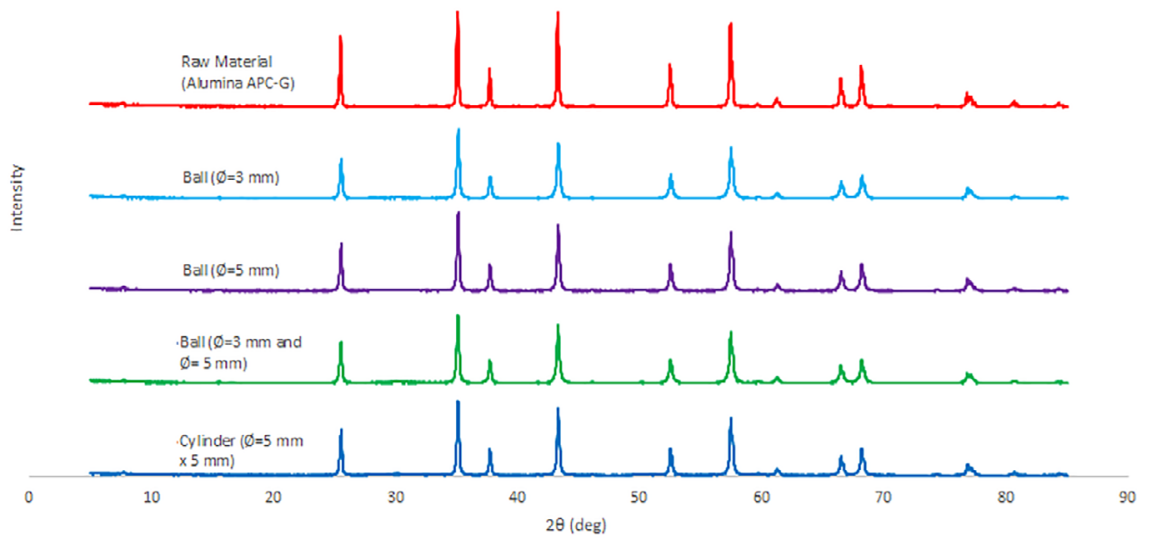

Figure 5. X-ray powder diffraction of the raw material and products. 
Although the planetary mill can be used for mechanochemical reactions ${ }^{14,22}$, the mechanical action in the processes discussed in this work was not sufficient to cause structural changes, which was expected since alphaalumina is a stable phase.

\section{Conclusions}

Because of the importance that grinding in planetary mills has been reaching, the effects media geometry (size and shape) on wet grinding of a planetary ball mill were experimentally analyzed in this work. Planetary mill test benches were manufactured and calcined alumina powder (a reference hard material) was ground under different conditions and the particle distributions were analyzed by a sedigraph.

The media geometry exerts significant influence on the grinding rate. Cylindrical media provided a coarser powder with a narrower distribution. On the other hand, small balls leads to smaller particle size. The mean particle size was reduced from $4.2 \mu \mathrm{m}$ to $1.1 \mu \mathrm{m}$ in 30 minutes in a mill with $150 \mathrm{~mm}$ of revolution ratio using $360 \mathrm{ml}$ jar filled with $3 \mathrm{~mm}$ balls. In all grindings there was no significant phase change. The experiments presented in this investigation can be used as an aid in the proper choice of grinding media or even to validate emerging models to study breakage in wet grinding.

\section{Acknowledgments}

This study was financed in part by the Coordenação de Aperfeiçoamento de Pessoal de Nível Superior - Brasil (CAPES) - Finance Code 001. The authors gratefully acknowledge the MTE Thomson for financial of prototype and analysis.

\section{References}

1. Mio H, Kano J, Saito F. Scale-up method of planetary ball mill. Chemical Engineering Science. 2004;59(24):5909-5916. DOI: https://doi.org/10.1016/j.ces.2004.07.020

2. Ashrafizadeh $\mathrm{H}$, Ashrafizaadeh M. Influence of processing parameters on grinding mechanism in planetary mill by employing discrete element method. Advanced Powder Technology. 2012;23(6):708-716. DOI: https://doi.org/10.1016/j. apt.2011.09.002

3. Roa DF, Buera MP, Tolaba MP, Santagapita PR. Encapsulation and stabilization of $\beta$-Carotene in amaranth matrices obtained by dry and wet assisted ball milling. Food and Bioprocess Technology. 2017;10:512-521. DOI: https://doi.org/10.1007/s11947-016-1830-y

4. Munkhbayar B, Nine MJ, Jeoun J, Bat-Erdene M, Chung H, Jeong $\mathrm{H}$. Influence of dry and wet ball milling on dispersion characteristics of the multi-walled carbon nanotubes in aqueous solution with and without surfactant. Powder Technology. 2013;234:132-140. DOI: https://doi.org/10.1016/j.powtec.2012.09.045
5. Briak-BenAbdeslam HE, Ginebra MP, Vert M, Boudeville P. Wet or dry mechanochemical synthesis of calcium phosphates? Influence of the water content on DCPD-CaO reaction kinetics. Acta Biomaterialia. 2008;4(2):378-386. DOI: https://doi. org/10.1016/j.actbio.2007.07.003

6. Ipek $\mathrm{H}$. The effects of grinding media shape on breakage rate. Minerals Engineering. 2006;19(1):91-93. DOI: https://doi. org/10.1016/j.mineng.2005.05.009

7. Ipek H. Effect of grinding media shapes on breakage parameters. Particle and Particle Systems Characterization. 2007;24(3):229235. DOI: https://doi.org/10.1002/ppsc.200601095

8. Kelsall DF, Stewart PSB, Weller KR. Continuous grinding in a small wet ball mill. Part V. A study of the influence of media shape. Powder Technology. 1973;8(1-2):77-83.

9. Liang YM, Zhao JH. Effect of zirconia particle size distribution on the toughness of zirconia-containing ceramics. Journal of Materials Science. 1999;34:2175-2181. DOI: https://doi. org/10.1023/A:1004588516105

10. Fruhstorfer J, Aneziris CG. Influence of particle size distributions on the density and density gradients in uniaxial compacts. Ceramics International. 2017;43(16):13175-13184. DOI: https://doi.org/10.1016/j.ceramint.2017.07.011

11. Khalil NZB, Vajpai SK, Ota M, Ameyama K. Effect of particle size distribution on $\mathrm{SiC}$ ceramic sinterability. Journal of the Japan Society of Powder and Powder Metallurgy. 2017;64(6):281-287. DOI: https://doi.org/10.2497/jjspm.64.281

12. Lilao AL, Forner VS, Gasch GM, Gimeno EM. Particle size distribution: a key factor in estimating powder dustiness. Journal of Occupational and Environmental Hygiene. 2017;14(12):975985. DOI: https://doi.org/10.1080/15459624.2017.1358818

13. Zhang FL, Zhu M, Wang CY. Parameters optimization in the planetary ball milling of nanostructured tungsten carbide/cobalt powder. International Journal of Refractory Metals and Hard Materials. 2008;26(4):329-333. DOI: https://doi.org/10.1016/j. ijrmhm.2007.08.005

14. Mio H, Kano J, Saito F, Kaneko K. Effects of rotational direction and rotation-to-revolution speed ratio in planetary ball milling. Materials Science and Engineering: A. 2002;332(1-2):75-80. DOI: https://doi.org/10.1016/S0921-5093(01)01718-X

15. Camargo IL, Fortulan CA, inventors. Disposição aplicada em moinho elou misturador planetário. BR patente 202018067623 2. 2018 Sep 3.

16. Camargo IL, Erbereli R, Lovo JFP, Fortulan CA. Planetary mill with friction wheels transmission aided by an additional degree of freedom. Machines. 2019;7(2):33. DOI: https://doi. org/10.3390/machines 7020033

17. Rosenkranz S, Breitung-Faes S, Kwade A. Experimental investigations and modelling of the ball motion in planetary ball mills. Powder Technology. 2011;212(1):224-230. DOI: https://doi.org/10.1016/j.powtec.2011.05.021

18. Chen Y, Lian X, Li Z, Zheng S, Wang Z. Effects of rotation speed and media density on particle size distribution and structure of ground calcium carbonate in a planetary ball mill. Advanced Powder Technology. 2015;26(2):505-510. DOI: https://doi. org/10.1016/j.apt.2014.12.007 
19. Takacs L, McHenry JS. Temperature of the milling balls in shaker and planetary mills. Journal of Materials Science. 2006;41(16):52465249. DOI: https://doi.org/10.1007/s10853-006-0312-4

20. Hüller M, Chernik GG, Fokina EL, Budim NI. Mechanical alloying in planetary mills of high accelerations. Reviews on Advanced Materials Science. 2008;18:366-374.
21. Fukumori Y, Tamura H, Jono K, Miyamoto M, Tokumitsu H, Ichikawa $\mathrm{H}$, et al. Dry grinding of chitosan powder by a planetary ball mill. Advanced Powder Technology. 1998;9(4):281-292. DOI: https://doi.org/10.1016/S0921-8831(08)60561-0

22. Balaz P. Mechanochemestry in nanoscience and mineral engineering. Berlin: Springer-Verlag; 2008. 